\title{
Pattern of maternal vaginal flora in labor and its effect on the newborn
}

\section{Vidya Singaravelu ${ }^{1}$}

${ }^{1}$ Dr.Vidya Singaravelu, Assistant Professor, Department of Pediatrics, DM Wayanad Institute of Medical Sciences, Naseeranagar, Meppadi, Wayanad, Kerala, India.

Corresponding Author: Dr. Vidya Singaravelu, Assistant Professor, Department of Pediatrics, DM Wayanad Institute of Medical Sciences, Naseeranagar, Meppadi, Wayanad, kerala, India E-mail: viddu7@gmail.com

\begin{abstract}
Background: Neonatal sepsis is the most important cause of morbidity and mortality in developing countries. Early onset sepsis is attributed to abnormal bacterial colonization of the maternal urogenital tract which leads to either an ascending but silent amniotic fluid infection or symptomatic chorioamnionitis. Aims \& Objectives: 1 . To study the pattern of maternal vaginal flora in labor. 2. To study the outcome in the neonate. Methods: This study was conducted on 250 mothers in labor \& their babies followed up till discharge in the departments of OBG \& neonatology in a tertiary care medical college hospital, Deliveries by caesarean section were excluded. Results: Out of 250 mothers $130(52 \%)$ of them showed colonization. Out of the 130 babies born to colonised mothers, 50 $(38.46 \%)$ showed features of sepsis, while only $10(8.34 \%)$ born to non-colonised mothers had features of sepsis. This study showed a statistically significant association between features of sepsis in babies and maternal vaginal colonization. Of the 60 babies with suspected sepsis, 40 had positive blood culture which is the gold standard investigation for sepsis. All of these culture positive babies i.e all 40(100\%) had maternal colonization with a statistically significant association. Conclusion: This study shows that maternal vaginal colonisation has significant association with neonatal sepsis. Hence, finding the organism in the maternal vaginal flora and treating it as per sensitivity might result less cases of neonatal sepsis.
\end{abstract}

Key words: Vaginal colonization, Neonatal sepsis, Blood culture positivity

\section{Introduction}

The new-born period is one of the phases of increased vulnerability to infections and this threat begins right from the intrauterine period and passage through the maternal birth canal.

Neonatal sepsis is the single most important cause of neonatal morbidity and mortality in the community, accounting for around $30-50 \%$. As many as $2 \%$ of fetuses are infected in utero, and up to $10 \%$ of infants have infections in the $1^{\text {st }}$ month of life [1].

The incidence of sepsis in developing countries is higher (1.8-18/1000) than the incidence in developed countries (1-5/1000). WHO reports that 5 million babies do not survive until 28 days age per

Manuscript received: $30^{\text {th }}$ November 2017

Reviewed: $10^{\text {th }}$ December 2017

Author Corrected: $18^{\text {th }}$ December 2017

Accepted for Publication: $24^{\text {th }}$ December 2017 year and $98 \%$ of mortality are from developing countries. Neonatal deaths in developing countries were caused by infections (42\%), asphyxia and birth trauma (29\%), preterm babies and low birth weight (10\%), congenital abnormalities (14\%) and other causes $(4 \%)$. Although the infection can be caused by viruses, fungi, and parasites, bacterial infection is the leading cause in neonatal sepsis [2].

The exposure that occurs during pregnancy or during childbirth is classified into early onset sepsis (early onset) and the exposure that occurs after birth is classified into slow-onset sepsis (late onset) [3].

Early onset sepsis is attributed to abnormal bacterial colonization of the maternal urogenital tract which leads to either an ascending but silent amniotic fluid infection or symptomatic chorioamnionitis [4]. 
Abnormal bacterial colonization of the rectum and anus during pregnancy may create an abnormal vaginal and cervical microbial environment. Studies in the West have revealed Group B Streptococcus (GBS) causing infection among 1-2/1000 live births with mortality rates up to $20 \%$ in affected neonates due to preterm labour, sepsis, respiratory distress and meningitis or sometimes benign asymptomatic colonization [5].

In developing countries where the incidence of neonatal sepsis is high and is the leading cause of mortality in the new-born, the role of GBS is not conclusively proved and many other organisms have been suspected to be instrumental [6].

Identification of the abnormal colonization of the genital tract by a culture based approach has been recommended by the CDC 2000. This will definitely aid in the early recognition of mothers who need to be effectively treated which in turn will prevent newborn infections.

Furthermore, a baseline knowledge of empirical antibiotic therapy in clinically suspected sepsis of early onset can be standardised and established in our situation. In the long run reduction in neonatal mortality and morbidity can be achieved [7].

\section{Aims \& Objectives}

1. To study the pattern of maternal vaginal flora in labor.

2. To study the outcome in the neonate

\section{Methods}

Place of study: This study was conducted on all mothers in labor and their newborns followed up till discharge in the departments of OBG and Neonatology in a tertiary care medical college hospital in Tiruvalla Kerala.

Type of study: The study was a cross sectional study conducted between September 2007 to August 2008.
Original Research Article

\section{Inclusion criteria}

1. 250 mothers in labor\& their newborn were included in the study.

2. Only mothers who underwent normal delivery were included

3. The aims and objectives of the study were explained to the mothers and the study was conducted after obtaining their consent.

Exclusion criteria- Deliveries by caesarean section were excluded. All mothers in labor were interviewed and detailed history taken regarding age, parity, socioeconomic status, antenatal problems. High vaginal swab was taken without local cleaning using Gusco's speculum from the posterior fornix as per CDC recommendations. The swab was then immediately transported to the microbiology lab and swabs were cultured using standard culture methods. The swabs were inoculated onto Blood agar, Chocolateagar, McConkey's agar and Thioglycolate medium and incubated and results evaluated at the end of 48-72 hours with the help of a qualified microbiologist. Group B Streptococcus was looked for by watching for lysis on blood agar.

The babies of these mothers were evaluated twice daily with regard to temperature, skin color, feeding, activity and those babies with suspected sepsis were identified. These babies were then subjected to Blood culture which is the gold standard for neonatal sepsis and other tests as the need demanded. These babies were given an empirical treatment with I.V antibiotics Ampicillin and Amikacin, the duration of which was determined by the culture reports. All the babies completed treatment successfully and were discharged in a healthy condition. The effect of various maternal parameters on vaginal colonization and the effect of maternal colonization on various neonatal parameters were studied.

Statistical analysis: Data analysis was done using Microsoft XL and Epi Info. Chi square test was used to assess the significance and ' $p$ value' of $<0.05$ was considered to be significant.

\section{Results}

250 mothers and their newborns were studied, out of which $130(52 \%)$ of them showed colonization \& remaining $120(48 \%)$ did not show any colonization.

Out of $130,84.6 \%$ of them showed colonization of single organism remaining $15.4 \%$ showed mixed growth. Total number of organisms identified were 150. Individual organisms \& their distribution is show in table 1.

Table-1: Distribution of various organisms. 
Original Research Article

\begin{tabular}{|c|c|c|}
\hline Name of the organisms & $\begin{array}{c}\text { Total number } \\
\mathbf{n = 1 5 0}\end{array}$ & Percentage \\
\hline Coagulase negative Staphylococcus & 30 & $13.3 \%$ \\
\hline E.coli & 20 & $13.3 \%$ \\
\hline Klebsiella & 20 & $13.3 \%$ \\
\hline Non-albicans Candida & 20 & $13.3 \%$ \\
\hline Candida Albicans & 20 & $7.33 \%$ \\
\hline Staphylococcus aureus & 11 & $6.66 \%$ \\
\hline Enterococcus & 10 & $6.66 \%$ \\
\hline Pseudomonas & 10 & $6 \%$ \\
\hline Non-fermenting GNB & 9 & \\
\hline
\end{tabular}

Table-2: Relation between age and vaginal colonization.

\begin{tabular}{|c|c|c|c|}
\hline Age & Growth & $\begin{array}{c}\text { No } \\
\text { growth }\end{array}$ & $\begin{array}{c}\text { Total } \\
\text { n=250 }\end{array}$ \\
\hline$<20 \mathrm{yrs}$ & $10(100 \%)$ & 0 & 10 \\
\hline $20-30 \mathrm{yrs}$ & $100(52.63 \%)$ & $90(47.37 \%)$ & 190 \\
\hline$>30 \mathrm{yrs}$ & $20(40 \%)$ & $30(60 \%)$ & 50 \\
\hline
\end{tabular}

Table 2 shows the effect of age on vaginal colonization. Of the 250 mothers 10 were below 20 years and all of them $(100 \%)$ were found to have vaginal colonization with a statistically significant $(\mathrm{p}<0.05)$ decrease in colonization with increasing age.

Table-3: Relation between parity and vaginal colonization.

\begin{tabular}{|c|c|c|c|}
\hline Parity & Growth & No growth & $\begin{array}{r}\text { Total } \\
\mathbf{n = 2 5 0}\end{array}$ \\
\hline Primi & $110(64.7 \%)$ & $60(35.3 \%)$ & 170 \\
\hline Non-primi & $20(25 \%)$ & $60(75 \%)$ & 80 \\
\hline
\end{tabular}

Table 3 shows the relation between parity and vaginal colonization. Out of the 250 mothers in labor, 170 were primigravida with $110(64.7 \%)$ of them having vaginal colonization, where as among the non-primi mothers $25 \%$ showed colonization. This study showed a statistically significant $(\mathrm{p}<0.05)$ association between primi mothers and vaginal colonization

Table-4: Relation between suspected sepsis and maternal colonization.

\begin{tabular}{|c|c|c|c|}
\hline Growth & Suspected Sepsis & Normal & Total \\
\hline Present & 50 & 80 & 130 \\
& $(38.46 \%)$ & $(61.54 \%)$ & 120 \\
\hline Absent & 10 & 110 & \\
\hline
\end{tabular}

Table 4: shows the relation between features of suspected sepsis in the new-borns and maternal vaginal colonization. Out of the 130 babies born to colonized mothers, 50 (38.46\%) showed features of sepsis, while only 10 (8.34\%) born to non-colonised mothers had features of sepsis. This study showed a statistically significant association between features of sepsis in babies and maternal vaginal colonization.

Table-5: Relation between blood culture positivity and maternal colonization. 
Original Research Article

\begin{tabular}{|c|c|c|c|}
\hline & Growth & No Growth & Total \\
\hline Blood c/s & 40 & 0 & 40 \\
Positive & $(100 \%)$ & 10 & 20 \\
\hline Blood c/s negative & 10 & $(50 \%)$ & \\
\hline
\end{tabular}

Table 5 shows the relation between blood culture positivity and maternal vaginal colonization. Of the 60 babies with suspected sepsis, 40 had positive blood culture which is the gold standard investigation for sepsis. All of these culture positive babies i.e. all $40(100 \%)$ had maternal colonization with a statistically significant association

In this study 40 babies had blood culture positive sepsis. All of them had colonized mothers. The predominant organism grown in the blood culture was Coagulase negative Staphylococcus (CoNS) (75\%) in 30 babies with 10 of their mothers having CoNS as the vaginal flora as well, with a blood culture and vaginal colonization showing a correlation in $33.33 \%$ of cases.

\section{Discussion}

The present study conducted in 250 pregnant women and their newborns conforms to previous studies in some aspects and points to some interesting observations contrary to previous studies in others. Neonatal sepsis causes about 718.000 deaths each year or about $23.4 \%$ of the 3.1 million deaths in 2010 [8]. Neonates are particularly vulnerable to infection in the first week of life. There are $42 \%$ of deaths in the first week of life caused by infection [9]. EONS (early onset neonatal sepsis) is generally caused by microorganisms that obtained from the mother before or during the birth process. Maternal genital tract organisms have an important role in EONS incidence[10]. Rectovaginal colonization of pregnant women was suspected to be a risk factor for neonatal sepsis within the first seven days of life [11].

The present study yielded Coagulase Negative Staphylococcus (CoNS) in $20 \%$ of the cases, followed by Escherichia Coli, Klebsiella, and Candida spp. In $13.3 \%$ of the cases. Hall etal also observed Coagulase Negative Staphylococcus (CoNS) as the most common organism in their study [12]. This is comparable to other Indian studies by Vidya Ayengar et al, Ahmedabad [13], Stoll Barbara et al [14] \& Habeebullah et al [15]which also did not yield GBS as the incidence of GBS colonization in India is quite low(19\%).

In a study from Delhi the most common organism isolated from maternal genital tract was Esch. coli followed by Staphylococcus aureus and KlebsiellaSpp [16].
Table 2 shows that $100 \%$ of mothers $<20$ years had colonization, whereas, it was $52.63 \%$ in $20-30$ years and $40 \%$ in $>30$ years, showing a statistically significant decreasing trend of colonization with increasing maternal age. This is comparable to the observations of Meharban Singh et al [17] which names maternal age of $<20$ years as one of the predisposing factors for vaginal colonization. The possible explanations could be either decreased local resistance due to thin vaginal epithelium or a relatively higher $\mathrm{pH}$; predisposing to colonization. From Table 3, vaginal colonization seems to be more in primipara $(64.7 \%)$ which conforms to the study by Meharban Singh et al [17] where in primipara are said to be at an increased risk of colonization.

Table 4 showed that 60 of the babies had suspected sepsis and $50(38.46 \%)$ of these were born to colonized mothers, while only $8.34 \%$ of them were born to non-colonized mothers. This conforms to the study by Vikas Gautam et al [18].

The present study showed that 50 of the 60 babies with suspected sepsis were born to colonized mothers and $40(80 \%)$ of these had confirmed sepsis i.e. blood culture positivity. It was found that of the 40 babies with blood culture positivity, all were born to mothers with vaginal colonization; and not a single one was born to non-colonized mothers. This was considered as a significant observation, given the $82 \%$ sensitivity and $96 \%$ specificity of blood culture in the detection of neonatal sepsis in accordance with the Edward Squire et al study [4].

In the present study, Co NS was grown in blood culture in $75 \%$ of cases, followed by Enterococcus in $10 \%$ of the cases, which was similar to E.S Shinewell et al [19]. Other similar studies have shown different 
organisms like Klebsiella \& CoNS [20] and Klebsiella, E. coli, Acinetobacter [21].

Rectovaginal bacterial colonization of pregnant women and chorioamnionitis has a positive correlation with the incidence of early-onset neonatal sepsis. Babies who born from mothers with chorioamnionitis lead to bacterial colonization and sepsis faster [22].

There are a number of parallels between maternal genital colonization with group B streptococcus and with E. coli. Both bacteria probably colonize the vagina from a rectal source and do not usually cause an infection of the vaginal epithelium. These two bacteria are of interest and concern because of their vertical transmission to the neonate and their role in neonatal sepsis, meningitis, and death [23].

\section{Summary}

- $38 \%$ of babies born to colonized mothers had suspected sepsis, compared to $8 \%$ in those born to non-colonised mothers.

- Blood culture positivity was found only in those babies born to colonized mothers.

- CoNS was the predominant pathogen in $75 \%$ of cases, followed by Enterococcus in 10\%.

- 10 mothers of babies with CoNS had the same organism as their colonizer, with $33 \%$ correlation in the pathogen

\section{Conclusion}

$52 \%$ of mothers in labor had vaginal colonization, predominantly CoNS.80\% of babies of these mothers had culture proven sepsis. The same organism was obtained in both mother and baby with sepsis in $33 \%$. Contrary to the western studies and our popular belief, Group B Streptococcus was not a significant issue in proven neonatal sepsis in the present study.

Acknowledgements: I sincerely thank my HOD Dr. Sushama Bai for guiding me in this project, and I thank Department of Obstetrics \& gynecology \& Department of Microbiology PIMS, Tiruvalla for rendering their support in completing my project.

Addition to current knowledge: Contrary to the western studies and our popular belief, Group B Streptococcus was not a significant issue in proven neonatal sepsis in the present study.

\section{Original Research Article}

Recommendations: Pattern of vaginal flora can guide antibiotic selection in neonatal sepsis in view of $33.33 \%$ similarity in growth. Institution wise study is recommended to identify the pattern of flora and antibiotic sensitivity. Periodic assessment of these studies need to be done to update the data.

Funding: Nil, Conflict of interest: None initiated, Perission from IRB: Yes

\section{References}

1. Stoll BJ. Infections of the Neonatal Infant. In: Kliegman, Behrman, Jenson, Stanton, editors. Nelson textbook of Pediatrics. $18^{\text {th }}$ ed. Philadelphia: Elsevier; 2007. p. 794

2. Child Health Research. Project special report: Reducing perinatal and neonatal mortality, report of a meeting. Baltimore, Maryland. 1999; 6-12.

3. Leal YA, Nemegyei JA, Velázquez JR, et al. Risk factors and prognosis for neonatal sepsis in south eastern Mexico. BMC Pregnancy Childbirth 2012; 12: 48 .

4. Yoon BH, Romero R, Moon JB, Shim SS, Kim M, Kim G, Jun JK. Clinical significance of intraamniotic inflammation in patients with preterm labor and intact membranes. Am J Obstet Gynecol. 2001 Nov;185(5):1130-6.

5. A Dwi Bahagia Febriani, Andi Handriyati, Ema Alasiry, Dasril Daud. The correlation between the mothers vaginal bacterial colonization and incidence of early onset neonatal sepsis. CurrPediatr Res 2017; 21 (1): 105-111

6. Klein J, Marcy M. Bacterial sepsis and meningitis. In Remington J, Klein J eds. Infectious Diseases of the Fetus and Newborn Infant, Ed 4. Philadelphia, WB Saunders, 1995; 835-890.

7. Squire E, Favara B, Todd J. Diagnosis of neonatalbacterial infection: hematologic and pathologicfindings in fatal and nonfatalcases. Pediatrics. 1979 Jul;64(1):60-4.

8. Liu L, Johnson HL, Cousens S, Perin J, Scott S, Lawn JE, Rudan I, Campbell H, Cibulskis R, Li M, Mathers C, Black RE; Child Health Epidemiology Reference Group of WHO and UNICEF. Global, regional, and national causes of child mortality: an 
updated systematic analysis for 2010 with time trends since 2000. Lancet. 2012 Jun 9; 379 (9832): 2151-61. doi: 10. 1016/ S0140-6736 (12)60560-1. Epub 2012 May 11.

9. Thaver D, Zaidi AK. Burden of neonatal infections in developing countries: a review of evidence from community-basedstudies. Pediatr Infect Dis J. 2009 Jan; 28(1Suppl):S3-9. doi: 10.1097 /INF.0b013e3181958755.

10. Basavaraj $\mathrm{MK}$, Bhat $\mathrm{BV}$, Harish $\mathrm{BN}$, et al. Maternal genital bacteria and surface colonization in early neonatal sepsis. Indian J Paediatrics 2006; 73: 29-32.

11. Seale AC, Blencowe $\mathrm{H}$, Manu AA, et al. Estimates of possible severe bacterial infection in neonates in sub-Saharan Africa, south Asia and Latin America for 2012: A systematic review and metaanalysis. Lancet Infect Dis. 2014 Aug;14 (8): 731741

12. Hall SL, Hall RT, Barnes WG. Relationship of maternal to neonatal colonization with coagulasenegative staphylococci. Am J Perinatal. 1990; 7(4): 384-8

13. Vidya Ayengar, Madhulika, Vani SN. Neonatal sepsis due to vertical transmission from maternal genital tract. Indian J Pediatric. 1991; 58(5) 661-664

14. Stoll Barbara J, Schuchat Anne. Maternal carriage of group B streptococci in developing countries. The Pediatric Infectious Disease Journal. 1998; 17(6): 499-503

15. Habeebullah S, Vishnu Bhat B, Basavaraj Kerur M, Harish BN. Maternal genital bacteria and surface colonization in early neonatal sepsis. Indian J Pediatr. 2006; 73(1): 29-32.

\section{Original Research Article}

16. Beargie R, Lynd P, Tucker E, Duhring J. Perinatal infection and vaginal flora. Am J Obstet Gynecol. 1975 May 1;122(1):31-3.

17. Singh M, Deorari AK. Pneumonias in newborn babies. Indian J Pediatr. 1995 May-Jun;62(3):293306.

18.Vikas Gautam, Pallab Ray, Anil Narang. Blood culture confirmed bacterial sepsis in neonates in a north Indian tertiary care center: Changes over the last decade. Jpn. J. Infect.Dis. 2009; 62(1):46-50.

19.E. S.Shinwell'Y. Matrai-Kovalskis, D.Greenberg, D. Fraser. Positive blood cultures for coagulasenegative staphylococci in neonates: Does highly selective vancomycin usage affect outcome? Infection. 1998; 26(2): 85-92

20. Bhat BV, Pandey KK, Raghavan M, Kanugo R. Bacteriological profile of blood culture isolation from neonates. Indian Journal of Maternal and Child Health. 1994 Oct-Dec; 5(4): 114-6

21. Habeebullah S, Vishnu Bhat B, Basavaraj Kerur M, Harish BN. Maternal genital bacteria and surface colonization in early neonatal sepsis. Indian J Pediatr. 2006; 73(1): 29-32.

22.Chan GJ, Baqui AH, Modak JK, Murillo-Chaves A, Mahmud AA, Boyd TK, Black RE, Saha SK. Early-onset neonatal sepsis in Dhaka, Bangladesh: riskassociated with maternalbacterial colonisation and chorioamnionitis. Trop Med Int Health. 2013 Sep;18(9):1057-1064. doi: 10.1111/tmi.12150. Epub 2013 Jul 4.

23. Marijane A. Krohn, SoeSoe Thwin, Lorna K. Rabe. Vaginal colonization by Escherichia coli as a risk factor for very low birth weight deliveries and other perinatal complications. The Journal of Infectious Diseases. 1997; 175(3): 606-610

\section{How to cite this article?}

Vidya Singaravelu. Pattern of maternal vaginal flora in labor and its effect on the newborn. Int J Pediatr Res. 2017;4(12):740-745.doi:10.17511/ijpr.2017.i12.07. 